\title{
Análise de livre interpretação como uma possibilidade de caminho metodológico
}

\author{
Free interpretation analysis as a methodological path possibility
}

\author{
Maylta Brandão dos Anjos ${ }^{1}$; Giselle Rôças² ${ }^{2}$ Marcus Vinicius Pereira ${ }^{3}$
}

1 Doutora, Instituto Federal do Rio de Janeiro, Nilópolis, RJ, Brasil - maylta.anjos@ifrj.edu.br / 0000-0001-6272-5056

2 Doutora, Instituto Federal do Rio de Janeiro, Nilópolis, RJ, Brasil - giselle.rocas@ @ifrj.edu.br / 0000-0002-1669-7725

3 Doutor, Instituto Federal do Rio de Janeiro, Nilópolis, RJ, Brasil - marcus.pereira@ ifrj.edu.br / 0000-0002-8203-7805

\section{Recebido em 20/06/2019. Publicado em Dezembro/2019}

\section{Palavras-chave:}

Análise de Livre

Interpretação. Ensino de

Ciências. Metodologia da

Pesquisa. Análise

Discursiva.

\section{Keywords:}

Free Interpretation Analysis. Science Education. Research Methodology. Discursive Analysis.
RESUMO: Neste artigo, apresentamos uma proposta de análise de dados para as pesquisas da área de ensino de ciências pautada no paradigma da metodologia qualitativa que denominamos Análise de Livre Interpretação (ALI), visando aliar a experiência dos professores-pesquisadores ao referencial teórico-metodológico ao qual se afiliam. Para tal, a ALI se situa em um rol em que a compreensão teórica busca atender à proposta e objetivos da pesquisa, discutindo suas bases na união da teoria trabalhada e dos elementos subjetivos próprios a quem disserta, pesquisa e ministra aulas simultaneamente. O professor-pesquisador, ao analisar os dados coletados, é capaz de extrapolar as bases teóricas na medida em que realiza inferências pautadas em um quadro de observações de vivências que acontecem entre participantes da pesquisa e pesquisadores. A proposta, em síntese, é que os aportes teóricos ofereçam movimentos interpretativos para compreensão dos vários quadros que podem emergir no campo de buscas e que esses contribuam para a expansão das reflexões, mostrando a livre harmonia interpretativa entre teoria e prática, entre refletir e fazer.

ABSTRACT: In this article, we present a proposal of data analysis for science education research area based on the paradigm of the qualitative methodology that we call Free Interpretation Analysis (FIA), aiming at allying the experience of teachers-researchers to the theoretical and methodological reference to which are affiliated. For this, the FIA is situated in a role in which the theoretical understanding seeks to meet the proposal and objectives of the research, discussing its bases in the union of the theory worked and the subjective elements themselves to those who lecture, research and teach classes simultaneously. The teacher-researcher, when analyzing the data collected, is able to extrapolate the theoretical bases insofar as he makes inferences based on observations of experiences framework that happen between research participants and researchers. The proposal, in summary, is that the theoretical contributions offer interpretive movements for understanding the various frames that may emerge in the search field and that these contribute to the expansion of the reflections, showing the free interpretive harmony between theory and practice, between reflecting and doing. 


\section{INTRODUÇÃO}

Mudar o mundo, amigo Sancho, não é loucura nem utopia, mas sim justiça. (Dom Quixote, Miguel de Cervantes)

Iniciar as reflexões propostas neste artigo com Dom Quixote, sobretudo em um momento em que sonhos e utopias se fazem cada vez mais necessários, se traduz em uma rica busca de aprendizado e ensino acerca daquilo que grita para a humanidade em justiça, um dos afetos soberanos da vida. É, portanto, apostar naquilo que temos de melhor, o nosso sonho de liberdade que se abriga e se faz amiga do nosso labor, e, nesse caso, de trabalhos científicos a bem do humano e da sociedade, apresentando o que de melhor se empreende na nossa capacidade de produzir em análise fenômenos da vida.

Esse cavaleiro de Cervantes que trazemos na epígrafe da seção nos aponta uma razão de existência. O que segue em nossas reflexões busca, nessa literatura, sua inspiração. Neste ensaio levantamos considerações que partem, em síntese, do nosso lugar de pesquisadores da área de Ensino de Ciências com atuação no Programa de Pós-graduação Stricto Sensu em Ensino de Ciências em uma instituição pública no Rio de Janeiro. Iniciamos, portanto, tratando de argumentações que nos inserem nos caminhos do processo acadêmico/científico, em suas possibilidades de formação das inferências e de explicação da realidade, que redundam na liberdade dialogada, analítica e lógica da interpretação.

Nesse sentido, apresentamos o processo da Análise de Livre Interpretação (ALI) como proposta de metodologia de análise de dados em pesquisas de cunho qualitativo, na medida em que traz ao texto e às teorias uma fundamentação de inferências multifatoriais em torno das temáticas de pesquisa levantadas em campo.

\footnotetext{
A abordagem multirreferencial propõe-se a uma leitura plural de seus objetos (práticos ou teóricos), sob diferentes pontos de vista, que implicam tanto visões especificas quanto linguagens apropriadas às descrições exigidas, em função de sistemas de referências distintos [...], ou seja, heterogêneos (ARDOINO, 1998, p. 24).
}

Kincheloe e Berry (2007) defendem que produzir conhecimento e interpretá-lo se configura como um ato complexo e que requer constante reflexão sobre a realidade, $\mathrm{o}$ arcabouço teórico e o paradigma metodológico ao qual o pesquisador se circunscreve. Assumindo a perspectiva de Rodrigues et al. (2016), compreendemos uma aproximação entre a proposta da Análise de Livre Interpretação (ALI) e a bricolagem científica ou epistemológica, que pode "ser vista como maneira pós-moderna de fazer pesquisa que, de certa forma, contribui para a profanação ou o questionamento da ciência como campo 
fechado, intransponível e restrito a círculos seletos e reservados" (RODRIGUES et al., 2016, p. 969).

Nossa intenção é que possamos definir alguns conceitos para a viabilidade da ALI nos pautando no que é observado no campo da pesquisa, o qual consideramos como soberano. A proposta não se esvazia nos "achismos" de uma observação rasa, mas que ocorre dentro de um repertório que não cessa em criatividade, sob um referencial teórico e desenho metodológico de uma pesquisa de cunho qualitativo, reforçados pelo estudo e nas sensibilidades advindas do olhar diferenciado para o campo de pesquisa vivido por muitos professores-pesquisadores ${ }^{1}$. Essa criatividade ancora-se em pesquisas qualitativas do pensamento científico, que se manifesta como chancela de interpretação ao professorpesquisador que está situado no mundo da investigação minuciosa e propositada, constituindo-se, portanto, em um enfoque interpretativo da realidade que se faz de vários instrumentos constitutivos da vida humana.

$\mathrm{Na}$ perspectiva de autores que trabalham com aportes metodológicos de pesquisa, buscamos inspiração e base de fala em Freire (2000; 2007), Demo (2002; 2004; 2006), Marconi e Lakatos (2003), Bortoni-Ricardo (2004; 2006), Dascal (2006), Minayo (2010; 2013), entre outros. Conquanto esses nos levam à discussão e a uma interpretação própria de que para a pesquisa qualitativa há um vasto campo interdisciplinar, multifacetado, polifônico, policromático e dialogal que atravessa as humanidades existentes nas ciências sociais, nas ciências naturais e nas ciências exatas, tendo foco um acervo multi-analítico, multi-estrutural, multi-organizacional e em multiformas que permite localizarmo-nos em espaços para além dos métodos que enquadram, padronizam, suprimem espontaneidades, limitam intuições e reduzem espaços de liberdade e de livre pensar.

\section{DE ONDE PARTIMOS: NOSSOS INSPIRADORES}

A partir da leitura de nossos inspiradores (os autores supracitados), buscamos aportes metodológicos para frisar os momentos e a feitura de uma pesquisa. Reconhecemos a importância de que não devemos suprimir os espaços de seguranças criativas e de inovações de pensamento que tornam o trabalho de uma investigação inédito, autoral, característico e de qualidade, ainda que respeitado e respaldado pelo referencial teórico-metodológico que circunscreve cada pesquisa.

\footnotetext{
${ }^{1}$ Entendemos como professor-pesquisador o profissional da área de ensino que cursa pós-graduação.
} 
Assim, é com base nas observações e experiências profissionais que ganhamos, atuando há anos em ensino em sala de aula, orientação, pesquisa e extensão, que nos arriscamos a dizer que podemos compreender os dados colhidos durantes as pesquisas para além das "amarras" de dispositivos analíticos que encarceram as palavras e ideias. Compreendemos que há uma pesquisa mais refinada, sobre a qual partimos para uma reflexão acerca de uma análise interpretativa, que coloca a experiência humana, o empirismo e as subjetivações como uma forma autoral de imaginação, de análise e práticas socioeducacionais oriundas das delimitações dadas aos objetos de pesquisa, sobretudo quando esse se revela na pesquisa do e no ensino de ciências no chão da escola. Propomos, aqui, uma ruptura com o modelo de que o "cientista" precisa sempre ser exato, imparcial, neutro, objetivo e apto a medir tudo e todos a fim de conhecer a "realidade" em que vive ou que pesquisa (HENNING, 2007).

Começamos em uma seara em que a interlocução caminha no sentido da incorporação, recriação e apropriação do campo metodológico, como passo de observações que visam às conexões de conhecimentos e saberes, se colocando em pauta para o entendimento dos fenômenos do mundo e dos sujeitos dentro desses fenômenos. Reconhecemos que a interação do saber existe em si própria e no que se apreende, em teoria, se fortalecendo em enlaces de compreensão que esmiúça um saber, desvelando o que parecia não estar tão claro ou transparente.

A compreensão e a interação dos saberes e conhecimentos apreendidos levam a uma interpretação que reflui no campo de análise de uma pesquisa, na solicitação de um olhar do pesquisador de forma mais leve, responsável e livre de juízos de valor que cerceiem campos observatórios. Elas requerem um recorte interpretativo entre a história pessoal, daquele que se faz observador específico de um cenário, de uma situação, envolvendo fenômenos e acontecimentos, com a realidade social, educacional e cultural, tendo claro que a "capacidade de compreensão do observador está enraizada em seus próprios significados, pois ele (ou ela) não é um relator passivo, mas um agente ativo" (BORTONI-RICARDO, 2004; 2006). Não é, portanto, mais fácil ou cômoda, pelo contrário, espinhosa e tortuosa, pois se faz necessário uma imersão na tríade campo de pesquisa, referencial teórico e metodologia. É essencial compreender o "por quê?" e/ou o "para quê?" ao iniciar uma pesquisa, para, depois, definirmos o “como?”, o “onde?”, o “com quem?”, o “para quem?” etc..

Nesse sentido, Dascal (2006) enfoca a significação num compromisso metodológico que tem, na argumentação e na sistematização, elementos centrais da compreensão e das interações - e pesquisa, na sua metodologia, não se dá sem ela. Por isso, são bem vindos meios semióticos de análise da linguagem. O campo é permeado, também, dessa linguagem. 
Destarte, a pesquisa qualitativa, com enfoque no ensino de ciências, é também, pesquisa de intervenção, e para tanto, como aponta Minayo (2010; 2013), é de bom tom termos claros os conceitos, as práticas e as teorias explicitadas e analisadas nas suas principais correntes do pensamento e na réplica a esses pensamentos. Ainda pautados nessa autora, compreendemos que a pesquisa, por se constituir como um processo vivo, está aberta a contextualizações e influências dadas por seus momentos socioeducacionais, econômicos e culturais; portanto, está também, na imersão da pesquisa e da metodologia que a conduz, um campo constituído para além de sua realidade que abraça as incursões subjetivas e intersubjetivas das relações permeadas por ela.

Ao fazer uso de uma lente com zoom "ciência e cientificidade" no ensino de ciências, focando a proposta da ALI, tendo por base os autores trazidos anteriormente, vimos que a compreensão da realidade é condição si ne qua non para o pesquisador se envolver e perceber com maior afinco o mundo, os fenômenos, os processos e fatos, e, assim, poder processar, com maior propriedade, a análise das expressões humanas presentes nas relações, nos sujeitos e nas representações objetivas e subjetivas da realidade, cercando a temática trabalhada no entendimento e compreensão das mediações e relações existentes no olhar do pesquisador. Ao analisar o corpus de uma pesquisa sob essa perspectiva, as categorias de análise emanam não somente da teoria, mas também da habilidade criativa e da experiência vivenciada pelo professor-pesquisador.

Nesse aspecto, a entrada do pesquisador em campo merece cuidados que envolvem questões éticas e de prática teórica que refluem e se configuram na análise do campo de pesquisa (MINAYO, 2010; 2013). Apesar de defendermos o reconhecimento da parcialidade e da não neutralidade do "cientista", é preciso criar mecanismos metodológicos para afastamento do texto, dos dados colhidos e da aplicação, para, assim, ser possível invocar a realidade vivida como um professor-pesquisador.

Amparados no pensamento de Freire (2000, 2007), arriscamos dizer que, ao proceder a análise teórico-metodológica da pesquisa, o professor-pesquisador na qualidade de observador levanta considerações não somente com os dados contextuais do campo de análise, mas também sobre uma sorte de fatores que se interligam aos participantes da pesquisa, às referências que serviram de base para o olhar minucioso em torno do objeto investigado, ao espaço e/ou cenário trabalhado, ao tempo de execução e ao tempo de reflexão, bem como a outros pontos que caminham na busca da construção da intersubjetividade para constituição do conhecimento à interpretação. A leitura analítica objetiva serve ao amadurecimento intelectual, à capacidade de perceber as nuances que carregam as falas e à discussão mais refinada dos dados da pesquisa. 
Portanto, em uma ALI, a compreensão se dá dentro de um conceito de interação comunicativa, que tem na escrita fonte demarcatória do discurso, dos traços produzidos por esse. Nesse sentido, a ALI vai ser somada ao conhecimento em que se aportou o professorpesquisador, na experiência pessoal de cada sujeito envolvido na pesquisa, nas relações que dispõem canais verbais e não verbais, como forma de interações que comungam compreensão e captação dos contextos circundantes e comunicativos. Esses são constitutivos de uma autorização ao pensamento expresso nos pressupostos e de tudo mais que o acompanha como análise - reflexão, intuição, razão, emoção, elaboração, leituras e concepções de realidade bem como as significações das falas e dados que remetem ao passaporte e à autenticidade no fazer da pesquisa.

Falas, por exemplo, apresentadas como narrativas de análise são passíveis de interpretações que fogem ao veio meramente pragmático colocado em foco de observação. Elas devem passar pelo crivo da reflexão, da compreensão dos significados e significantes, abrangendo ou levando o professor-pesquisador a perceber a visão do todo para, a partir daí, dirimir e explicitar o esquema que está para além da fala, que está entre a fala e a escuta, entre o que se expressa nela. Assim, é também estar atento aos silêncios e interjeições expressas por ela.

Os pontos apresentados situam-se entre a sensibilidade e a objetividade da arrumação do texto verbal. A liberdade de interpretar significados localiza e autoriza o professorpesquisador ao exercício de si, do outro e dos entre "sis" não ditos, mas expressos nos olhares, nos gestuais, na respiração, nas formas etc.. Por isso, estabelecer métodos no que nasce livre é, por muitas vezes, limitar poderes de análises interpretativas, é subtrair riquezas de diálogos, de consciências que brotarão no encontro e na busca do entendimento das palavras. É, muitas vezes, subtrair autoria e capacidade criativa que nasce na espontaneidade de se permitir autor de um intertexto contextual entre aqueles que produzem diferentes ideias e se entendem, ou não, pela comunicação. É, por vezes, contrariar ou desqualificar a experiência de um professor-pesquisador, cuja observação aliada à teoria permite a emergência de categorias mais realistas quando não são oriundas necessariamente e exclusivamente da teoria. Nessa linha, a ALI se alinha ao entendimento do método da bricolagem, quando

não busca descobrir verdades, como se elas estivessem escondidas à espera de um investigador, o que se pretende é entender a sua construção e questionar como os diversos agentes sociais produzem e reproduzem o que é imposto pelos discursos hegemônicos. Ora, teorias e conhecimentos nada mais são do que artefatos culturais e linguísticos. Uma vez que a interpretação está imbricada na dinâmica social e histórica que moldou o artefato cultural sob análise, a bricolagem reconhece a inseparabilidade entre objeto de pesquisa e contexto (NEIRA e LIPPI, 2012, p.610). 
É nesse sentido que a teoria alimenta a análise e é feita por ela. O pesquisador, ao ter clareza sobre a ALI, estará dotado do aporte que lhe serve de base do começo ao fim, terá uma apropriação textual objetivada no pensamento e/ou na réplica dos autores trabalhados. Sua indagação será sempre se está de fato a compreender a mensagem dos participantes de sua pesquisa no texto dado, à luz do referencial teórico-metodológico, estabelecimento como norte desde o início da pesquisa, desde o delineamento da pergunta e da inquietação que o moveu.

Dessa forma, se manter atento ao tema das narrativas e das nuances que elas possuem é fator importante dentro do processo da ALI, pois requer do pesquisador uma constante atenção aos problemas e reflexões que suas referências (bibliográficas e não bibliográficas) apresentarem. A interpretação terá em foco a ideia central, inteirando-se as ideias secundárias expressas nas falas. A análise se fará na reconstrução de um percurso que não perca o raciocínio do pesquisado, das ideias constituídas pelo texto verbal e não verbal no seu processo lógico.

Sendo assim, a ALI terá na argumentação a explicitação e na proposição um encadeamento de sua tese em um processo coerente, no qual a análise foi estruturada mediante as ideais apresentadas pelos autores referenciais que decupados, compreendidos, dialogados e apropriados, alargaram a visão, proporcionaram possibilidade do ver além, ouvir de forma apurada o outro, sentir os fonemas na representação da vida. É a partir dessa compreensão, evocada muito mais que o senso objetivo e pragmático das questões, que a mensagem comunicada pelos participantes da pesquisa nos autoriza a interpretar o dito e a antever o axioma pelo que não estava dito. Numa compreensão profunda de posição e análise própria a respeito das ideais enunciadas, supera-se a estrita mensagem, levando o professorpesquisador a perceber o que diz as entrelinhas, as nuances da fala, o gestual de apoio ou contraditório da fala.

A ALI, portanto, se coloca e se apresenta numa fecundidade dialogal, dialética, com os autores de referências do trabalho de pesquisa, com o professor-pesquisador e com os participantes que discursaram, anunciando seu pensamento, sob argumentação sólida, lúcida, coerente com as premissas, dentro de um princípio crítico sobre as temáticas ali propostas a serem investigadas.

Como propositiva de análise em uma pesquisa em ensino de ciências, a ALI deve ampliar as possibilidades de uma experiência que se dá no fazer criativo do professorpesquisador, expresso na relação com o mundo, com o objeto de sua pesquisa, consigo e com o outro. Tal escolha pelo caminho analítico leva a uma dedicação profunda ao olhar dos sujeitos investigados, fazendo com que a construção de narrativas experienciais e vivas 
aconteça e transpareçam na espontaneidade da fala, que se expande na vivência e no desenvolvimento das relações entre o objeto do estudo naquele que vive e naquele que observa, escuta e interpreta.

Por conseguinte, é a partir da compreensão das falas que a síntese das ideias é trabalhada de forma profunda, em que as narrativas são passadas em revistas para se ter elementos mais profundos para reflexão. Porquanto, o campo de análise em que as pesquisas em ensino de ciências ocorrem é permeado por debates oriundos dos conflitos e contradições das metodologias e dos aportes a serem investigados. Nesse ínterim, há, no campo das ciências, diversos campos de análise que caminham em sentidos da unidade, outros no sentido da crise e outros abarcam a diversidade. Tais fatos são sinônimos que revelam as contradições, as réplicas e os entrevistos da pesquisa que estão presentes na identidade que permeia a relação entre os participantes da pesquisa e objeto investigado.

Baseados nos autores que nos inspiraram, nos diálogos que realizamos com eles e a partir deles, extraímos que a pesquisa, por muitas vezes, representa um trabalho artesanal e de debruce profundo, em que a espontaneidade, a criatividade e a liberdade devem compor uma metodologia que se realiza, fundamentalmente, por uma linguagem baseada em conceitos, proposições, pressupostos e caminhos de narrativas que se constroem entre o particular e o coletivo, entre o empírico e a sua análise, entre o apresentado e o que ele representa. Logo, o caminho da pesquisa está sempre a ser feito, pois toda metodologia reflete possibilidade de novas descobertas, de novos estares, de crescimento, de amplidão de pensamento. Se ela acontece em um estado de prazer e liberdade, temos um conhecimento produzido com novas indagações, novas visões, novas contribuições que pavimentam a estrada que a metodologia nos mostrou.

\section{E HÁ TÉCNICA!?!?!?}

É importante ressaltar que, neste artigo, nos propusemos a um diálogo inicial, em que nos indagamos se há técnica para a construção de um caminho metodológico de uma pesquisa que se pretenda enquadrar como uma ALI, e afirmamos que, para responder a essa indagação, uma estrada há que se trilhar. Dessa forma, temos a intenção de considerar a pesquisa como espaço aberto de inovações, pensamentos e de novas práticas de ação. Sendo assim, consideramos que os autores tidos como referenciais e mencionados no aporte teórico das pesquisas, nas suas diferentes compreensões e narrativas, linguagens e compreensões, amplificam, contextualizam, fortalecem e dinamizam a significação e caracterização de trajetos exploratórios da investigação. 
Assim, na definição e redefinição dos caminhos metodológicos da pesquisa, as relações contidas nela são objetos de negociações, esclarecimentos, exposição de conflitos, de onde se veem como realizações para aproximações teóricas em um conjunto de trajetórias, de experimentações no mundo que refletem a singularidade frente a outros fenômenos e situações (MARCUSCHI, 2008).

Nesse contexto, algumas reflexões são necessárias para se por em movimento uma proposta que já habita em nós, ou seja, quase sempre é uma palavra-chave, um agente motivador, um afeto ou um prazer que se apresenta como elemento essencial à análise. Para tanto, é importante na pesquisa a consecução de uma metodologia em que o pesquisador se sinta capaz de realizar suas elaborações pessoais ao mesmo tempo em que se apropria de uma linha teórica que alimenta seu argumento e fundamenta sua análise de forma lógica, coesa e proposital. A síntese do que foi percebido no campo é fator meticuloso, porque não pode subtrair ou esvaziar contextos importantes de observação. O desenvolvimento das ideias dos autores referenciais que mediaram o debate, bem como daqueles elementos relacionados com eles, deve fluir de forma inteligível. Na escrita acadêmica deve-se, portanto, coadunar a metodologia, o objeto de investigação e a metodologia, propiciando interesse ao leitor. Ademais, ela significa também valioso exercício de raciocínio, amadurecimento intelectual. Essa etapa se apoia na retomada de pontos abordados em todas as etapas anteriores, no que foi extensivamente lido e trabalhado em momentos anteriores de uma pesquisa (KOCH, 2004).

A contribuição trazida pelos autores referenciais com que dialoga o professorpesquisador em sua escrita acadêmica dará possibilidade de fazer inferências no contexto científico expresso dos temas, levando-o ao entendimento das "entrelinhas", a fim de desvelar as concepções e compreensões no sentido de estabelecer interações entre as leituras, estudos sobre o tema, para que assim possa problematizar, inferir, indagar, interpretar de forma chancelada pelo background teórico, agora apropriando sua forma autoral de entender uma determinada questão.

O exercício da crítica, das réplicas e das concordâncias com as teorias que embalaram, conversaram e se contrariaram ao tema deverão estar presentes na ALI. Na prática, isso significa levantar e discutir problemas com relação ao objeto investigado e trazer à cena, no potencial da análise, uma problemática pela qual se busca aprofundamento, soluções, registros, conexões e discussões que levam a caminhos de considerações e conclusões.

Em resumo, para se proceder a uma ALI é necessário que o professor-pesquisador, conhecedor do background teórico, reconheça a pluralidade de interpretações que uma fala, situação ou texto suscita. Para tal, recorrer ao contexto narrativo, ao aspecto da cena, a 
intermediação dos objetos e a tudo que expressa a realidade, dá pistas para que a interpretação seja autorizada e validada pela ancoragem estabelecida e que fundamenta a análise do objeto investigado. É no ato da pesquisa, no fazer dela legitimado pela percepção relacional entre os aspectos teóricos e metodológicos, que se potencializa a capacidade argumentativa da ALI.

\section{À GUISA DA CONCLUSÃO}

Temos claro que a proposição da Análise de Livre Interpretação (ALI) neste artigo apenas descortina o início de uma possibilidade metodológica para a área de Ensino de Ciências. Nesse sentido, pretendemos, com esse início, que nossos leitores contribuam com a ALI e "dialoguem com nossas ideias, que nos rebobinem ou nos avancem, seja por meio de ensaios em resposta, de editoriais em periódicos ou de qualquer outro veículo que ecoe na comunidade de ensino de ciências. Esse é um exercício importante que precisamos estimular" (PEREIRA e RÔÇAS, 2018, p. 323-324). Há que se ter mais debates para organizarmos e tecermos uma teia que possa moldar um aparato teórico e metodológico para a ALI, levando em conta a complexidade conceitual que gira em torno dos caminhos metodológicos de uma pesquisa qualitativa.

É importante destacar que nossa proposta não ecoa em um vazio, já que em algumas de nossas pesquisas, nos trabalhos de alguns professores-pesquisadores, nossos orientandos de mestrado e doutorado, nas discussões suscitadas em nossos grupos de pesquisa, já trilhamos caminhos para implementação da ALI que esperamos, muito em breve, estarem publicados no sentido de exemplificar e demonstrar a sua viabilidade, avaliando a robustez e as fragilidades de uma metodologia de análise que se inicia e se circunscreve no real cotidiano de um professor-pesquisador.

As discussões das relações entre os aspectos teóricos e metodológicos remetem às diferentes ideias do fazer e do como se fazer pesquisa. A proposta de uma ALI requer que se pense de forma apropriada as significações e os significados dos temas e objetos de pesquisa trabalhados, que deverão estar afinados. Ainda apoiados em Pereira e Rôças (2018), tais aspectos da ALI vão de encontro à (e não ao encontro de) ingênua, falha e falaciosa prática de pesquisa que tem habitado o imaginário de jovens "pesquisadores" ao produzirem seus textos "Frankenstein", pouco autorais, sem tempo de maturação, recortados e mutilados, recheados de citações "lego" e "muleta" (salami science), que parecem se preocupar apenas com a selvagem competição por produtividade a todo e qualquer preço, na contramão de movimentos como o slow science (RÔÇAS; ANJOS; PEREIRA, 2017). 
É essa constante revisão e repensar que faz com que as metodologias dispostas ao ensino de ciências possam ser revistas em conceitos, teorias e métodos, podendo se superar sempre na intenção de manter uma viva chama de mudanças e reestruturações que reacende novas consciências de que o que se aprende e/ou descobre é sempre provisório, é sempre ponto de interlocução para surgimento de outras narrativas e pensares. É como dissemos em nossas orientações: o produto de uma pesquisa - um artigo, um produto educacional, uma dissertação, uma tese etc. - nunca é um ponto final, mas sim um ponto-e-vírgula.

Dessa forma, o que está contextualizado ao seu tempo, mais a frente se tornará obsoleto, porque, finalmente, o que há de se reconhecer sempre são as realizações que abriram as portas para novos surgimentos e novas reformulações. Por isso, ainda que não nos pareçam, métodos são provisórios. E é nesse sentido que a recomendação feita pelo personagem IDEA, no romance de Murakami (2018) intitulado "O assassinato do comendador", ganha uma tônica interessante para se refletir:

São pouquíssimas as coisas que posso contar aos jovens senhores sobre essa obra [...]. Isso porque a sua essência é uma alegoria, uma parábola. E alegorias e parábolas não devem ser explicadas em palavras, devem ser engolidas.

\section{AGRADECIMENTO}

À Fundação Carlos Chagas Filho de Amparo à Pesquisa do Estado do Rio de Janeiro (FAPERJ), à Coordenação de Aperfeiçoamento de Pessoal de Nível Superior (CAPES) e ao Conselho Nacional de Desenvolvimento Científico e Tecnológico (CNPq), por apoiarem os autores deste ensaio.

\section{REFERÊNCIAS}

ARDOINO, J.. Abordagem multirreferencial (plural) das situações educativas e formativas. In: BARBOSA, J. G. A. (Org.). Multirreferencialidade nas ciências e na educação. São Carlos: EdUFSCar, 1998.

BORTONI-RICARDO, S. M.. Educação em língua materna: a sociolinguística em sala de aula. 2. ed. São Paulo: Parábola, 2004.

Nós cheguemo na escola, e agora? Sociolinguística e educação. 2. ed. São Paulo: Parábola, 2006.

DASCAL, M.. Interpretação e Compreensão. São Leopoldo: Unisinos, 2006.

DELL'ISOLA, R. L. P.. Leitura: inferências e contexto sociocultural. Belo Horizonte: Formato, 2011. 
DEMO, P.. Complexidade e Aprendizagem: a dinâmica não linear do conhecimento. São Paulo: Atlas, 2002.

. Pesquisa Participante: saber pensar e intervir juntos. Brasília: LiberLivros, 2004.

. Éticas Multiculturais: sobre convivência humana possível. Petrópolis: Vozes, 2006.

DENZIN, N. K.; LINCOLN, Y. S.. Introdução: a disciplina e a prática da pesquisa qualitativa. In . (Org.). Planejamento da pesquisa qualitativa: teorias e abordagens. Porto Alegre: Artmed, 2006.

FREIRE, P.. Educação como prática da liberdade. Rio de Janeiro: Paz e Terra; 2000. . Ação cultural para a liberdade e outros escritos. Rio de Janeiro: Paz e Terra; 2007.

HENNING, P. C.. Profanando a ciência: relativizando seus saberes, questionando suas verdades. Revista Currículo sem Fronteiras, v. 7, n. 2, p. 158-184, 2007. Disponível em: <http://www.curriculosemfronteiras.org/vol7iss2articles/henning.pdf>. Acesso em: 12 abr. 2019.

KINCHELOE, J. L.; BERRY, K.. Pesquisa em educação: conceituando a bricolagem. Porto Alegre: Artmed, 2007.

KOCH, I. V.. A inter-ação pela linguagem. São Paulo: Contexto, 2004.

MARCONI, M. de A.; LAKATOS, E. M.. Fundamentos de metodologia científica. 5. ed. São Paulo: Atlas, 2003.

MARCUSCHI, L. A.. Produção textual, análise de gênero e compreensão. São Paulo: Parábola Editorial, 2008.

MINAYO, M. C. de S. (Org.). Pesquisa social: teoria, método e criatividade. Petrópolis: Vozes, 2010. O desafio do conhecimento: pesquisa qualitativa em saúde. São Paulo: Hucitec, 2013.

MURAKAMI, H.. O assassinato do comendador. Traduzido por Rita Kohl. Vol. 1. São Paulo: Alfaguara, 2018.

NEIRA, M. G.; LIPPI, B. G.. Tecendo a colcha de retalhos: a bricolagem como alternativa para a pesquisa educacional. Educação e Realidade, v. 37, n. 2, p. 607-625, 2012. Disponível em: 〈https://dx.doi.org/10.1590/S2175-62362012000200015>. Acesso em: 12 abr. 2019.

PEREIRA, M. V.; RÔÇAS, G.. "Rebobine, por favor": como avaliamos as pesquisas na área de ensino de ciências? Revista Brasileira de Ensino de Ciência e Tecnologia, v.11, n.2, 2018. Disponível em: <https://periodicos.utfpr.edu.br/rbect/article/view/8457>. Acesso em: 12 abr. 2019.

RÔÇAS, G.; ANJOS, M. B.; PEREIRA, M. V..Quanto vale ou é por quilo: o peso da produção acadêmica na área de ensino. Ensino e Tecnologia em Revista, v. 1, n. 1, p. 46-66, 2017. Disponível em: <https://periodicos.utfpr.edu.br/etr/article/view/5949>. Acesso em: 12 abr. 2019. 
RODRIGUES, C. S. D.; THERRIEN, J.; FALCÃO, G. M. B.; GRANGEIRO, M. F.. Pesquisa em educação e bricolagem científica: rigor, multirreferencialidade e interdisciplinaridade.

Cadernos de Pesquisa, v. 46, n. 16, p. 966-982, 2016. Disponível em:

<https://dx.doi.org/10.1590/198053143720>. Acesso em: 12 abr. 2019.

\section{SOBRE OS AUTORES}

MAYLTA BRANDÃO DOS ANJOS. Doutora em Ciências Sociais. Professora do Instituto Federal do Rio de Janeiro (IFRJ) e da Universidade Federal do Estado do Rio de Janeiro (UNIRIO). Docente e pesquisadora dos Programas de Pós-Graduação Stricto Sensu em Ensino de Ciências (PROPEC) e em Educação Profissional e Tecnológica (PROFEPT) do IFRJ Atuou na concepção do tema, diálogo em grupo, redação do texto e levantamento das referências.

GISELLE RÔÇAS. Doutora em Ecologia. Professora do Instituto Federal do Rio de Janeiro (IFRJ). Docente e pesquisadora do Programa de Pós-Graduação Stricto Sensu em Ensino de Ciências (PROPEC) do IFRJ. Atuou na redação do texto a partir de debates crítico-reflexivos entre os autores e levantamento das referências.

MARCUS VINICIUS PEREIRA. Doutor em Educação em Ciências e Saúde. Professor do Instituto Federal do Rio de Janeiro (IFRJ). Docente e pesquisador do Programa de PósGraduação Stricto Sensu em Ensino de Ciências (PROPEC) do IFRJ e do Programa de Pósgraduação em Educação em Ciências e Saúde (PPGECS) do NUTES/UFRJ. Atuou na redação do texto a partir de debates crítico-reflexivos entre os autores e levantamento das referências. 